\title{
Relationship between oceanic mesozooplankton and energy of eddy fields
}

\author{
S. A. Piontkovski ${ }^{1}$, R. Williams ${ }^{2, *}$, W. Peterson ${ }^{3}$, V. K. Kosnirev ${ }^{4}$ \\ 'Institute of Biology of the Southern Seas, 335011 Sevastopol, Ukraine \\ ${ }^{2}$ Plymouth Marine Laboratory, West Hoe, Plymouth PL1 3DH, United Kingdom \\ ${ }^{3}$ NOAA/NMFS -F/RE3, 1335 East West Highway, Silver Spring, Maryland 20910, USA \\ ${ }^{4}$ Marine Hydrophysical Institute, 2 Kapitanskaya Str., 335000 Sevastopol, Ukraine
}

\begin{abstract}
The impact of mesoscale eddies on the spatial distribution of zooplankton biomass was analysed using data from the Arabian Sea and the Black Sea. The highest values of spatial variance of zooplankton biomass in the upper 100 to $150 \mathrm{~m}$ were found in regions with maximum available potential energy of the eddy fields. Diel temporal trends of zooplankton biomass were observed in the Arabian Sea area. However, the input of the macroscale spatial (horizontal) component of summarised spatio-temporal variability of the zooplankton fields exceeded the input of the diel temporal component.
\end{abstract}

KEY WORDS: Zooplankton biomass $\cdot$ Arabian Sea $\cdot$ Black Sea $\cdot$ Spatial distribution

\section{INTRODUCTION}

The influence of ocean eddies on the spatial-temporal structure and functioning of plankton communities has been the subject of study by several national and international programmes (Wiebe et al. 1976, Ortner et al. 1979, Kosnirev \& Shapiro 1981, Ring Group 1981, Bradford et al. 1982, Tranter et al. 1983, Haury 1984, Piontkovski et al. 1985). These and the other investigations emphasised the important role of mesoscale and synoptical eddies in forming the structure and productivity of marine planktonic communities and consisted the basis of several overviews (Owen 1981, Angel \& Fasham 1983, Mann \& Lazier 1991, Olson 1991). Eddies can enhance primary production several times through nutrient injection into the euphotic zone (Falkowski et al. 1991).

Mesoscale eddies are observed in 2 main forms, as single eddies and as eddy fields (Korotaev 1980). Single eddies as a rule possess a high stock of potential energy enabling them to exist in space and time from months to years. The dynamics of eddies forming 'high

·Addressee for correspondence. E-mail: sep@pml.ac.uk packed' eddy fields in the open ocean are quicker but the energy stock of single elements is lower. From a biological point of view single eddies have been studied more than eddy fields. Examples of this research are seen in the studies of the energy intense eddies, known as 'rings', associated with the Gulf Stream, the East Australian Current and the California Current System. Studies of open ocean fields of eddies are less numerous and have never been summarised, even though open ocean planktonic communities represent the most extensive biological systems on Earth. It should be noted that for single eddies and eddy fields the quantitative relationships between the characteristics of the heterogeneity of the planktonic fields and the energy characteristics of the eddies themselves have never, to our knowledge, been reported. To evaluate these relationships from a statistical viewpoint, intensive macroscale field surveys are required.

Data from 2 expeditions, one to the Arabian Sea and the other to the Black Sea, were used to address questions of (1) how the eddy fields affect the spatial heterogeneity of the zooplankton biomass field and (2) whether consistent quantitative relationships exist between energy characteristics of the eddy field and 
indicators of the spatial heterogeneity of the zooplankton fields.

\section{METHODS}

Parameterization of the physical structure. A variety of mechanisms exist which generate mesoscale eddy fields. For example, Gulf Stream rings, Kuroshio rings, and eddies of the Black Sea are formed mainly as the result of meanders breaking off from the main flow because of baroclinic unstability of stream-flows (Fuglister \& Worthington 1951, Golding \& Symonds 1978, Monin \& Ozmidov 1981, Blatov et al. 1984). Eddies are also formed from flow over seamounts and banks (Ebbesmeyer \& Taft 1979) and from current interactions (Plotnikov et al. 1985). Because of the various types of eddies and their different forms of generation, attempts have been made to classify them (Nelepo et al. 1984). Despite the diversity of origin of eddy types in the ocean, there is a unifying feature in all eddies and/or during some phase of their existence, which is the vertical motions induced in part by mesoscale rotary motion, which leads to deviation of isopycnal surface from equilibrium. These in turn can lead to upwelling of deeper water to the surface. The available potential energy (APE) can be used as the integrative characteristic of the deviation of isopycnal surfaces:

$$
\mathrm{APE}=\frac{1}{2} g^{2} / \zeta_{0} \int_{0}^{h} \zeta^{2} / N^{2} \mathrm{~d} Z
$$

where $N^{2}$ is the square of the Brent-Vaisala frequency, $\zeta$ is the perturbation of water density at a given depth $\mathcal{Z}, g$ is the acceleration of gravity, and $\zeta_{0}$ is the mean water density. The higher the amount of APE in an eddy, the greater the deviation of the isopycnal surfaces from equilibrium positions.

The macroscale grid areas in our studies were divided into squares, where the background density distribution was assessed by a formula of the linear trend, by the method of least squares: $\hat{\sigma}_{t}=A x_{j}+B y_{j}+$ $C$. The coefficients here represent values of zonal and meridional gradients of the relative water density $\sigma_{l}$ at each depth. The total APE of a field is represented as $A P E_{\text {sum }}=A P E_{\text {eddies }}+\mathrm{APE}_{\text {background }}$. The latter is mainly formed by the macroscale interseasonal processes, considered as the background for eddy-scale events.

$$
\begin{aligned}
\mathrm{APE}_{\text {eddies }} & =\frac{1}{\mathrm{n}} \sum_{i j}\left[\left(\hat{\sigma}_{t}\right)_{i j}-\left(A x_{j}+B y_{j}+C\right)\right]^{2} \\
\mathrm{APE} & =\frac{1}{\mathrm{n}} \sum_{i j}\left[\left(A x_{j}+B y_{j}+C\right)-\hat{\sigma}_{t}\right]^{2}
\end{aligned}
$$

where $\mathrm{n}$ is the number of stations in a square, $\hat{\sigma}_{i}$ is water density averaged over squares, $A, B$ are coefficients (values of zonal and meridional density gradients at each depth, i.e. 10, 15, $20 \mathrm{~m}$ etc.).

Grids. The Indian Ocean grid took $19 \mathrm{~d}$ to complete (March-April 1980) and consisted of 117 stations. The spatial resolution between stations was about $110 \mathrm{~km}$ latitude and $75 \mathrm{~km}$ longitude (Fig. 1). The Black Sea grid survey was completed in $15 \mathrm{~d}$ (August-September 1980) and consisted of 114 stations with a spatial resolution of about $110 \times 55 \mathrm{~km}$ between stations. However, in this work only data from the open waters were used (60 stations). At each station, CTD profiles and zooplankton net samples were obtained. To assess APE characteristics, the Arabian and Black Sea surveys were divided into 5 and 3 squares respectively. For each of these squares the averaged APE was calculated. Their value was compared with spatial variance of zooplankton biomass calculated from stations within these squares. This procedure was repeated for each of the squares, to provide the relationship given in Fig. 4.

Bogorov-Rass nets used in the Indian Ocean study (80 $\mathrm{cm}$ mouth diameter, $112 \mu \mathrm{m}$ mesh) and the oceanic model of the Juday nets used in the Black Sea $180 \mathrm{~cm}$ mouth diameter, $145 \mu \mathrm{m}$ mesh) were towed vertically (0 to $100 \mathrm{~m}$, Indian Ocean; 0 to $150 \mathrm{~m}$, Black Sea) at 0.7 to $1.0 \mathrm{~m} \mathrm{~min}^{-1}$. Typically, 50 to $75 \mathrm{~m}^{3}$ of water was filtered during the collection of each sample. The filtered volume was estimated from wire out, angle, mouth diameter of the net and duration of tow. Sample biomass together with the zooplankton fraction was estimated by volume on board ship. A full species identification was carried out back in the laboratory.
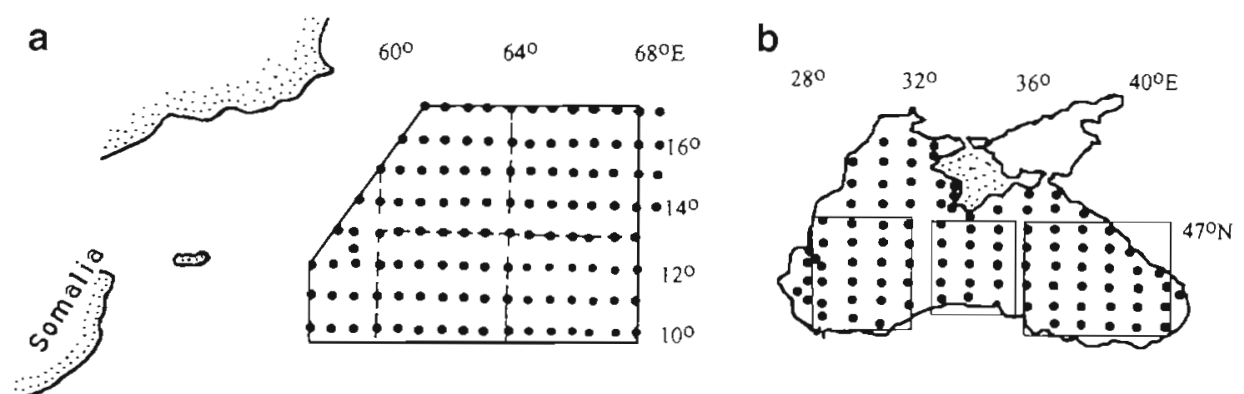

Fig. 1. Grids of stations in (a) the Indian Ocean and (b) the Black Sea. Grids were partithoned into 5 squares in the Indian Ocean and 3 squares in the Black Sea 


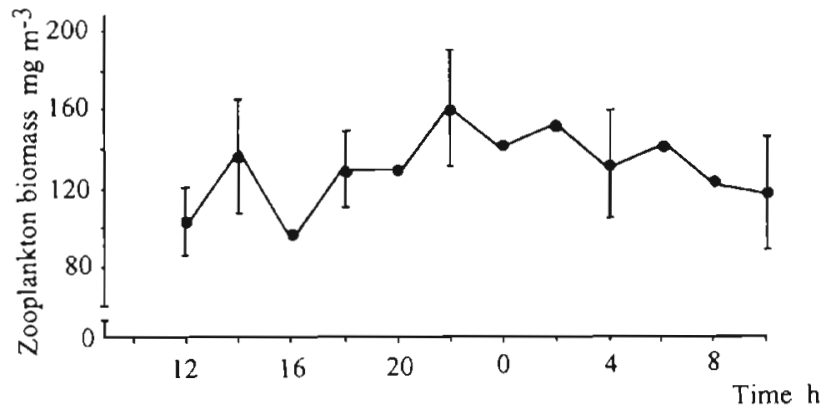

Fig. 2. Diel trend of zooplankton biomass in the Indian Ocean (0 to $100 \mathrm{~m}$ layer). Vertical bars represent standard deviations

Because stations were sampled during day and night, it was necessary to estimate and remove the impact of diel zooplankton migrations on the assessments of horizontal spatial distribution. In order to determine the average diel variability of zooplankton biomass in the integrated (i.e. 0 to 100,0 to $150 \mathrm{~m}$ ) layers, the following procedure was used: a day was divided into 12 intervals of $2 \mathrm{~h}$ each, and zooplankton biomass values measured during the grid survey were distributed in these intervals (08:00-10:00, 10:0012:00, 12:00-14:00 $\mathrm{h}$ etc.). The average biomass was calculated for each interval and represented in a form of a time-dependent curve (Fig. 2). This curve was smoothed in order to obtain the final trend of the diel temporal zooplankton biomass. The ratio $B_{\mathrm{i}} / B_{x}$ was calculated for each interval (where $B_{1}$ is the interval averaged and smoothed biomass; $B_{x}$ is the average (for all intervals) diel biomass. Biomass values at each station (B) were divided on the ratio $B_{i} / B_{x}$ according to position of $B_{1}$ and $B_{\mathrm{j}} / B_{x}$ in the temporal interval. This final procedure removed the diel temporal trend of biomass caused by vertical migrations of zooplankton. These modified data were used for subsequent analysis.

The diel trend was not observed in the data from the Black Sea grid. Therefore the primary (not detrended) field data were used in further analysis of the spatial distribution of zooplankton biomass and its association with water dynamics.

\section{RESULTS}

The structure of the Indian Ocean eddy field could be observed on plots of dynamical topography (Fig. 3). Within the area of the grid, the density of eddies is high and the geostrophic current was estimated to be 10 to $20 \mathrm{~cm} \mathrm{~s}^{-1}$ (Kosnirev \& Shapiro 1981). An element of macroscale cyclonic circulaton in the south and eastern part of the area is evident in the plot. This circulation was formed during the winter monsoon in the Arabian Sea and continued to exist even after the monsoon decreased in intensity. Current speeds in this feature were the same as in eddies; the current structure could be observed down to $800 \mathrm{~m}$.

The distribution of zooplankton biomass presented here (Fig. 3b) differs from those published (Samyishev 1981) because the diel trend (Fig. 2) was removed from the primary data set. In general, high values of biomass are concentrated in the northern part of the grid area. Local maxima exist and are mainly located on the peripheral zones of eddies, or regions where eddies interact with a system of main currents.

Copepods comprised up to $68-75 \%$ of zooplankton in the samples and were represented primarily by 7 genera, Clausocalanus, Paracalanus, Acrocalanus, Calanus, Oithona, Oncaea and Corycaeus. The majority of the larger copepods came from the following genera, Undinula, Pleuromamma, Euchaeta and Scolecithrix. Chaetognaths and ostracods were also abundant in the plankton samples (Samyishev 1981).

The relationship between spatial heterogeneity of zooplankton biomass $\left(S^{2} / x\right.$, where $S^{2}$ is the spatial variance of biomass inside 3 to $4^{\circ}$ squares of the grid, and $x$ is the mean biomass of each square) and APE
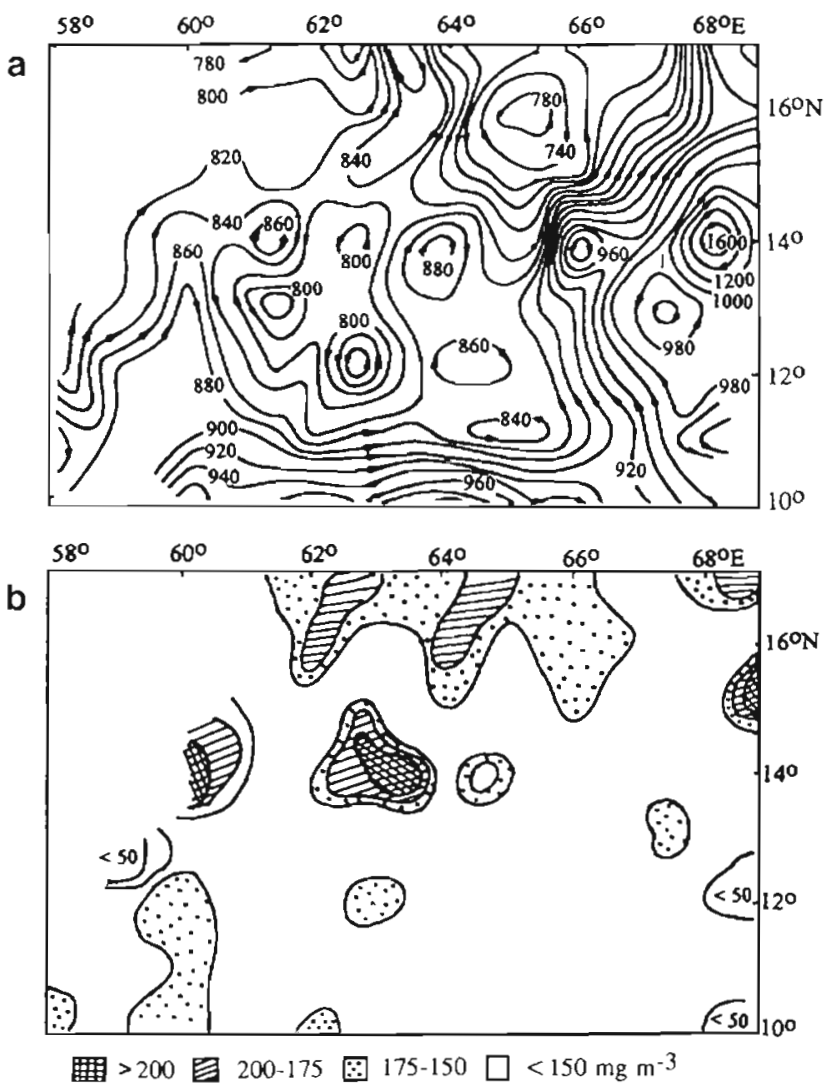

Fig. 3. (a) Dynamical topography (dynamical heights in dynamical centimetres, from Kosnirev \& Shapiro 1981) and (b) zooplankton biomass (wet weight, modified data from Samyishev 1981) in the 0 to $100 \mathrm{~m}$ layer in the Indian Ocean 
indicates that the highest spatial heterogeneity of zooplankton biomass takes place in regions with the highest energy potential of the eddy fields as well as the highest energy potential of the summary APE (Fig. 4a). The latter makes the relationship weaker because of the impact of the 'noise' induced by the background component. From the analysis of variance for the full regression, $r^{2}=0.8$ (standard error of estimation $=1.97$; Durbin-Watson statistic $=2.52 ; F$-ratio $=3.8$, p-value $=$ $0.2)$. The lines joining the data points in Fig. 4 contour the space of coordinates of the expected relationship. as was recommended by Tukey (1981). Using such a method we do not derive the definitive form of a quantitative relationship (the regression curve, for instance), but trace the $X-Y$ space, within which these relationships are expected.

The dynamical topography of the Black Sea during the 1980 survey exhibited the main current along the northern margin of the sea. Intense eddies in the southwestern and eastern portions of the sea, and
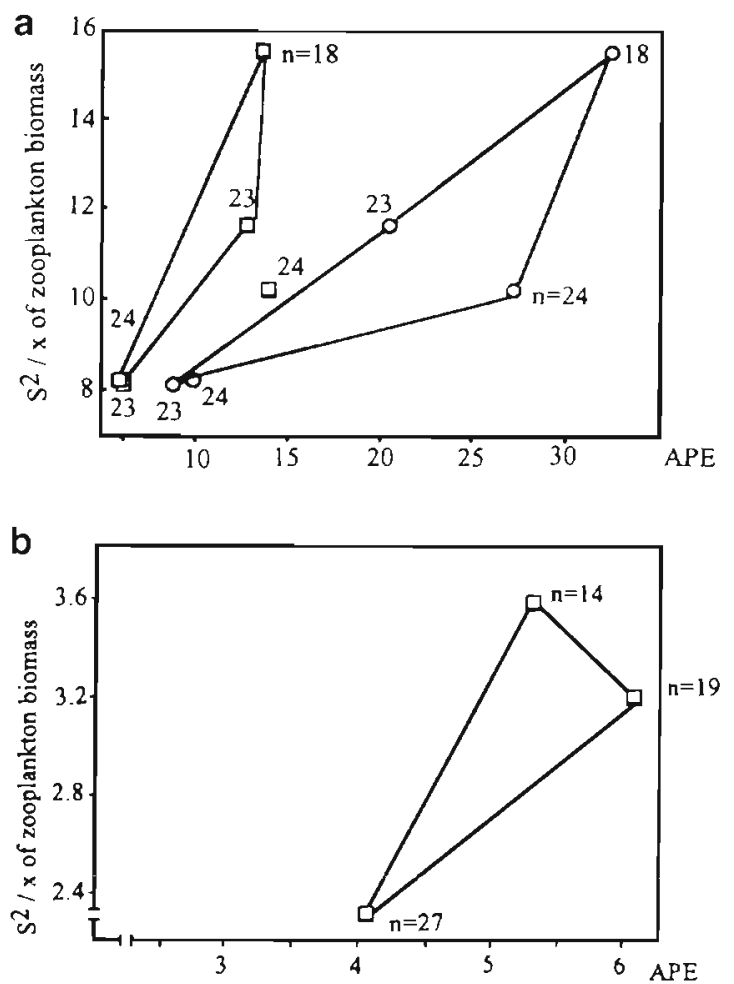

Fig. 4. Relationship between the heterogeneity of the spatial distribution of zooplankton biomass $\left(S^{2} / x\right.$, where $S^{2}$ is biomass spatial variance within squares partitioning a grid area, and $x$ is the mean biomass of each square) and the available potential energy (APE) of the hydrophysical field in (a) the Indian Ocean and (b) the Black Sea. (a) APE of eddies ( $O$; erg $\left.\mathrm{cm}^{-2} 10^{-6}\right)$; and total APE of the eddies and the background area ( $\square$ ). (b) Total APE of the eddies and the background area $\left(\mathrm{J} \mathrm{m}^{-2} 10^{-3}\right)$. $\mathrm{n}$ : number of measurements (stations) used to calculate a given value of $S^{2} / x$ other dispersed smaller eddies and meanders were observed. The current speeds in the main flow were approximately 8 to $10 \mathrm{~cm} \mathrm{~s}^{-1}$. Geostrophic current speeds in the smaller eddies were about 15 to $20 \mathrm{~cm} \mathrm{~s}^{-1}$ at the core and 4 to $8 \mathrm{~cm} \mathrm{~s}^{-1}$ on the periphery (Atsihovskaya et al. 1988). The mechanism of eddy generation in the Black Sea is the same as for western boundary currents (e.g. Gulf Stream rings), but lower levels of energy are transformed by the process (Blatov et al 1984)

Zooplankton biomass collections in the Black Sea were taken in the upper $150 \mathrm{~m}$ (Fig. 5). The abundant species in the zooplankton fraction were the copepods Pseudocalanus elongatus, Paracalanus parvus, Oithona nana, O. similis, Calanus helgolandicus, Acartia clausi, Anomalocera patersoni, Pontella mediterranea, although their composition varied over the studied area. Sagitta setosa, Oikopleura dioica and Noctiluca miliaris were the most abundant species in the 'noncopepod' fraction (see Zagorodnaya 1988).

In most cases enhanced values of zooplankton biomass were related to the peripheral zones of eddies and regions, where these eddies interact with the main stream. It goes without saying that such comparisons of maps of dynamical topography and plankton distributions should be considered as approximate since the dynamical method and procedure of the linear interpolation have built in errors. Similar to the results from the Indian Ocean grid, the relationship between spatial dispersion of zooplankton biomass and the APE in the Black Sea indicates that the highest spatial heterogeneity of zooplankton biomass is observed in regions with the highest potential of eddy field energy (see Fig. 4 b).

\section{DISCUSSION}

It is shown from the analysis of the periodical component of spatial-temporal variability of zooplankton biomass (Fig. 2), that in open oceanic waters zooplankton diel migrations, which mainly determine the periodical oscillation of biomass in tropical upper layers (Piontkovski \& Goldberg 1984), could impact on the results of the surveys of the spatial grids. Our data presentation (Fig. 2) gives the possibility to compare the imput of the diel component into the summarised spatial-temporal variability of the plankton field at a given scale range. In fact, the normalised standard deviation of 12 points of the trend curve (i.e. the coefficient of variation of the curve, $\mathrm{CV}=14 \%$ ) can characterise the intensity of temporal (diel) variability of zooplankton biomass, typical for the investigated areas.

On the other hand, vertical bars at each point of the curve indicate variability which is mainly caused by 
a

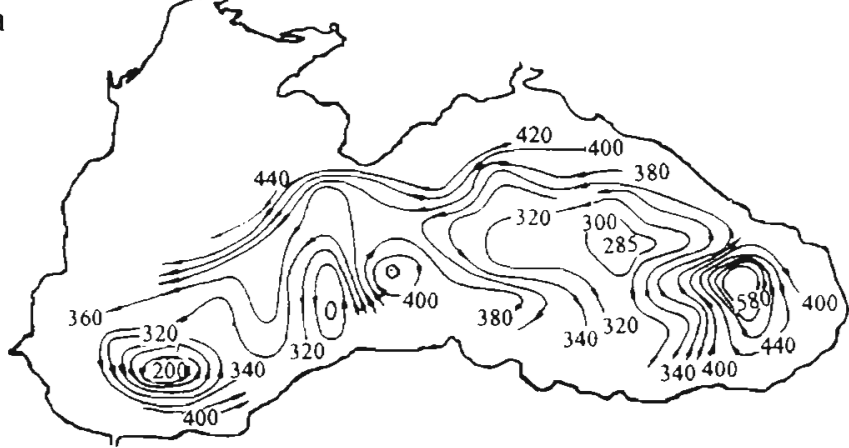

b

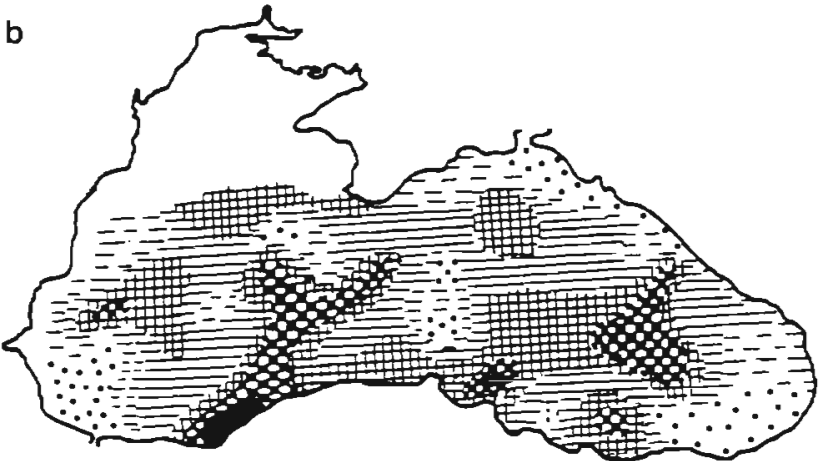

the basis of vertical hauls in the 0 to $200 \mathrm{~m}$ layer. They proposed that this trend was caused mainly by trophodynamics, i.e. reproduction of zooplankton and carnivory.

The link between biological production and eddy APE can be made if the vertical nutrient flux to the euphotic zone, coupled to vertical transport within the eddy, is a function of the APE. That is the higher the APE, the higher the upwelling and nutrient flux to the euphotic zone. This relationship must be qualified because the APE takes into account all processes leading to isopycnal surface deviation, but nutrient flux into the euphotic zone depends upon the existence of upward vertical transport. Thus, it is necessary to carefully distinguish regions of cyclonic and anticyclonic eddy motion

The level of biological production also depends upon the duration of an eddy's influence on a region. Eddies 200 to $300 \mathrm{~km}$ in diameter and moving at $15 \mathrm{~km} \mathrm{~d}^{-1}$ (as observed in Indian Ocean grid) influenced the plankton community at a given point for 10 to $20 \mathrm{~d}$, a time sufficient to significantly affect phytoplankton growth. In this case primary production measurements showed that regions of maximal phytoplankton production coincided with the positions of cyclonic eddies (Kuzmenko 1981). The same situation has been observed during the survey of the Black Sea, where local maxima of primary production were often located on the periphery of cyclonic eddies in open waters (Finenko 1988). These 2 examples provide support for the coupling between the effects of eddy fields on spatial structure and heterogeneity of plankton communities.

In any given ocean area, a number of different spatial horizontal heterogeneity of macroscale (hundreds of $\mathrm{km}$ ) distribution. These bars on the curve can be considered as the standard deviation at each time interval (10:00-12:00, 12:00-14:00 h etc.) from samples collected at the same time, but at different geographical regions within a grid. For different points on the curve this variability, when expressed in terms of $\mathrm{CV}$, is in the range 22 to $42 \%$. Thus, the ratio of macroscale spatial to temporal (diel) variability is close to 2 . Consequently, in the integrated layer the input of the macroscale spatial (horizontal) component of the variability of the plankton field is twice as high as the input from the temporal (diel) component. However, particularly in the upper mixed layer and in some regions of the Atlantic and the Indian Oceans, in the integrated upper layers ( 0 to 100,0 to $150 \mathrm{~m}$ ) the diel temporal variability exceeds the macroscale spatial variability (Piontkovski \& Goldberg 1984, Piontkovski et al. 1985).

In the Black Sea this temporal trend was not well developed, although Kovalev \& Zagorodnaya (1987) described the diel trend of zooplankton abundance on processes may give rise to solitary eddies or an eddy field. In the Indian Ocean, many of them are probably formed by Rossby wave emission during the meandering of a macroscale frontal zone and its decay in the intermonsoon period (Kosnirev \& Shapiro 1981). In this case, the process of eddy formation occurs during the passage of a wave and the isopycnal surfaces must be deflected upward with a consequent uplifting of the nutricline. The water is not permanently upwelled, but the uplifted zone travels with the wave. Since the duration of influence of such a moving uplifted zone at any location is on the order of $10 \mathrm{~d}$, phytoplankton may receive a nutrient pulse and bloom. The response by the zooplankton community to such a perturbation is likely to be small, because of the generation time of mesozooplankton. For example, the generation time of copepods in the Indian Ocean tropical zone is 1.5 to 3 times longer than phytoplankton and is approximately 15 to $30 \mathrm{~d}$. This is even the case when the 
concentration of food for herbivores and carnivores is very high (Sajina 1985).

Another cause of eddy field generation is the baroclinic instability of coastal currents of the Somalian and Arabian coasts. These coastal currents can generate eddies which subsequently move into the open ocean. Such eddies, moving from the Somalian coast to the oceanic regions of the Arabian Sea, are observed in images obtained from the NIMBUS-7 Coastal Zone Colour Scanner and are also documented from field research (Banse \& McClain 1986). On the basis of field measurements it has also been shown that some of these eddies have temperature-salinity characteristics of Arabian upwelled water which itself provides evidence for their meridional motion from north to south (Kosnirev \& Shapiro 1981).

The eddy field itself may cause an increase in the variability of zooplankton biomass through interactions between the zooplankton and the flow field. The mechanism of enhancement of the spatial heterogeneity of zooplankton distribution is probably based on the following events. Zooplankton are entrained in the peripheries of eddies which retain these organisms. The efficiency of this mechanism depends upon the critical distance of particles (organisms) from an eddy and the value of the horizontal turbulent diffusion coefficient. This coefficient defines the depth to which particles/organisms penetrate into the central part of the eddy. Results from modelling this process suggest that particles should concentrate in the central part when the critical distance is small and the horizontal turbulent diffusion coefficient is large (Eremeev \& Ivanov 1987). Eddies within an eddy field often interact, which leads to the formation of the frontal zones. Within these fronts convergence process takes place, which leads to the aggregation of the planktonic organisms and enhances the heterogeneity index $\left(S^{2} / X\right)$ of the spatial distribution of the zooplankton biomass. Eddies with enhanced APE should generate more 'contrasted' convergence zones (as APE transforms in time into kinetic and orbital eddy movement) which will lead to the aggregation of organisms.

Variations in current speed associated with an eddy field coupled to mass vertical movements of zooplankton, as a result of diel migration, can also cause redistribution and local aggregation of plankton animals.

In situations like those described above the observed correlation between the characteristics of the spatial heterogeneity of zooplankton biomass and the energy characteristics of the eddies allows an assessment and prediction of the mesoscale patchiness of zooplanktonic fields on the basis of physical parameters.

In some cases the effect of mesoscale eddies on zooplankton distribution might not be observed, and is associated more with larger-scale physical events. For example, it was shown from a single survey within the California Current System that a mesoscale eddy had little effect on the abundance of zooplankton and the local zooplankton maximum associated with the edge of the eddy was related more to the presence of coastal waters (Haury 1984).

The relationships between the energetic chracteristics of the hydrophysical fields and the plankton communities seem reasonable but they impinge on a further problem. This is the relationships between the energy flow (also as the energy stock) in a hydrophysical environment and the energy flow (also as the energy stock) in a pelagic community. In fact, values of biomass in Fig. 4 can be expressed also in energy units (i.e. erg $\mathrm{cm}^{-2} 10^{-6}$ ), which is the same dimension as the APE. In time, the APE of the hydrophysical field transforms into the energy of currents, the kinetic energy of eddies, their rotation etc. In time, the biomass of a community transforms throughout different planes. It transforms through the spatial-temporal scale, similar to that of water particles. From the other side, the biomass transforms and modifies as it moves through the trophic chain of a community. It predetermines the secondary production of zooplanktonic organisms, because the secondary production $(P)$ is proportional to the biomass $(B)$ with the coefficient of the specific growth (C): $P=C B$ (Zaika 1973).

As was previously mentioned, 2 main forms of eddies exist, the single eddy and the eddy field, which predetermines the approach to their study. In the case of a single eddy, the deterministic approach is perhaps more useful in the study of the eddy's impact on the spatial formation and functioning of the plankton community. Replicate physical-biological surveys of the eddy allow monitoring of the changes of parameters in space and time. Studies of the Gulf Stream rings serve as a good example of this type of research. In the study of an eddy field the affect of a single eddy is difficult to evaluate and in this case a statistical approach should be used to determine the impact of eddies on a plankton community spatial-temporal structure (Piontkovski et al. 1995). The above mentioned link between the spatial heterogeneity of the zooplankton biomass field and the APE field serves as an example. This link seems fairly sustainable, as examples are observed from different geographical regions and in eddy fields with different physical-dynamical characteristics. In order to ensure that these revealed patterns are more widespread, further data of simultaneous biological and hydrophysical measurements are required.

Acknowledgements. We are very grateful to Drs E. Z. Samyishev and Y. A. Zagorodnaya, whose data on zooplankton were used in our analysis. Drs L. R. Haury and P. H. Wiebe made very helpful comments on the furst version of the manuscript. 


\section{LITERATURE CITED}

Angel MV, Fasham JR (1983) Eddies and biological processes In: Robinson AR (ed) Eddies in marine sclence. SpringerVerlag, New York, p 492-524

Atsihovskaya JM, Andruschenko A.A, Truhchev DI, Kirikova MV, Regner Sl, Sergeeva LM (1988) Circulation, temperature-salinity and hydrochemical water structure of the Black Sea results from macroscale survey. In: Zats VV Finenko ZZ (eds) Water dynamics and plankton productivity of the Black Sea (Dynamica vod i productivnost planktona Chernogo morya). Acad Sci USSR, Moscow p 8-67 (in Russian)

Banse K. McClain CR (1986) Winter blooms of phytoplankton in the Arabian Sea as observed by the coastal zone color scanner. Mar Ecol Prog Ser 34:201-211

Blatov AS, Bulgakov NP, Ivanov VA (1984) Variability of the Black Sea hydrophysical fields (Izmenchivost gidrofizicheskih polei Chernogo morya). Hydrometeoizdat, Leningrad (in Russian)

Bradford JM, Heath RA, Chang FH, Hay CH (1982) The effect of warm-core eddies on oceanic productivity of northern New Zealand. Deep Sea Res 29(12A):1501-1516

Ebbesmeyer CC, Taft BA (1979) Variability of potential energy, dynamic height and salinity in the main pycnocline of the Western North Atlantic. J phys Oceanogr 9: $1073-1089$

Eremeev VN, Ivanov LM (1987) The tracers in the ocean parametrisation of the transport and the dynamics of numerical modelling. Naukova Dumka, Kiev (in Russian)

Falkowski PG, Ziemann D, Kolber Z, Bienfang PK (1991) Role of eddy pumping in enhancing primary production in the ocean. Nature 352:55-57

Finenko $Z Z$ (1988) Primary production during summer period. In: Zats VV, Finenko ZZ (eds) Water dynamics and plankton productivity of the Black Sea (Dynamica vod i productivnost planktona Chernogo morya). Acad Sci USSR, Moscow, p 315-323 (in Russian)

Fuglister FC, Worthington LV (1951) Some results of a multiple ship survey of the Gulf Stream. Tellus 3:1-14

Golding TJ, Symonds O (1978) Some surface circulation features of the Western Australia during 1973-1976. Aust J mar Freshwat Res 37:215-232

Haury LR (1984) An offshore eddy in the California Current System, Part IV, Plankton distributions. Prog Oceanogr 13: 95-111

Korotaev GK. (1980) The structure, dynamics and energy of the synoptical variability of the ocean (Stryktyra, dinamika i energiya sinopticheskoi izmenchivosti okeana). Marine Hydrophysical Institute, Sevastopol (in Russian)

Kosnirev VK, Shapiro NB (1981) Synoptical variability of the north-eastern part of the Indian Ocean (Synopticheskaya izmenchivost severo-zapadnoi chasti Indiiskogo okeana). Marine Hydrophysical Institute, Sevastopol (in Russian)

Kovalev AV, Zagorodnaya YA (1987) New dates and explanation of diel change in the number of marine planktonic animals. In: 3 Congress of Soviet Oceanologists ( 3 Congress sovetskih okeanologov), Leningrad, Vol 1, p 61-63 (in Russian)

Kuzmenko LV (1981) Primary production of the central surface waters of the Arabian Sea during summer and winter periods. In: Nelepo BN (ed) Complex oceanological research of the Indian Ocean (Komplesnye okeanologicheskie issledovaniya Indiiskogo okeana). Marine Hydrophysical Institute, Sevastopol, p 108-115 (in Russian)
Mann KH, Lazier JRN (1991) Dynamics of marine ecosystems: biological-physical interactions in the oceans. Blackwell Scientific Publ, Oxford

Monin AS, Ozmidov RV (1981) Oceanic turbulence (Okeanskaya turbulentnost). Hydrometeoizdat, Leningrad (in Russian)

Nelepo BA, Bulgakov NP, Blatov AS, Ivanov VA, Kosarev AN, Tujilkin VS (1984) The classification and distribution of synoptical eddies in the world ocean (Klassifikaciya i pasprostratenie sinopticheskih vihrevyih obrazovanii $v$ mirovom okeane). Marine Hydrophysical Institute, Sevastopol (un Russian)

Olson DB (1991) Rings in the ocean. A Rev Earth planet Sci 19:283-311

Ortner PB, Hulbert EM, Wiebe PH (1979) Phytohydrography, Gulf Stream rings, and herbivore habitat contrasts. J exp mar Biol Ecol 32:285-294

Owen RW (1981) Fronts and eddies in the sea: mechanism, interactions and biological effects. In: Longhurst ARL (ed) Analysis of marine ecosystems. Academic Press, New York, p 197-233

Piontkovski SA, Goldberg GA (1984) The ratio of spatial to temporal variability of planktonic fields. Ecology (Ekologiya) 1:42-46 (in Russian)

Piontkovski SA, Scherbatenko PV, Melnik TA (1985) Spatialtemporal characteristics of horizontal and vertical zooplankton distributions in the Indian Ocean. Pol Arhiv Hydrobiol 32(3/4):310-318

Piontkovski SA, Williams R, Melnik TA (1995) Spatial heterogeneity, bromass and size structure of plankton of the Indian Ocean: some general trends. Mar Ecol Prog Ser 117:219-227

Plotnikov VA, Bulgakov NP, Golovko VA (1985) Temperature-salinity structure of waters in south subequatorial divergence of the Indian ocean. Pol Arhiv Hydrobiol $32(3 / 4): 231-252$

Sajina LI (1985) Fecundity and growth rate in copepods from different dynamic zones of equatorial counter-current of the Indian Ocean. Pol Arhiv Hydrobiol 32(3/4):491-550

Samyishev EZ (1981) Trends of zooplankton development in the open waters of the Arabian Sea. In: Nelepo BA (ed) Complex oceanological research of the Indian Ocean (Komplesnye okeanologicheskie issledovaniya Indiiskogo okeana). Marine Hydrophysical Institute, Sevastopol, p 124-132 (in Russian)

The Ring Group (1981) Gulf Stream cold-core rings: their physics, chemistry and biology. Science 212:1091-1100

Tranter DJ, Tafe DJ, Sandland RL (1983) Some zooplankton characteristics of a warm-core eddy shed by the East Australian current, with particular reference to copepods. Aust J mar Freshw Res 34(4):587-608

Tukey $\mathrm{J}$ (1981) The analysis of the measurement results (Analiz rezultatov izmerenii). Mir, Moscow (in Russian)

Wiebe PH, Hulburt EM, Carpenter EJ, Jahn AE, Knapp GP, Boyd SH, Ortner PB, Cox JL (1976) Gulf Stream cold core rings: large-scale interaction sites for open ocean plankton communities. Deep Sea Res 23:685-710

Zagorodnaya YA (1988) Heterogeneity of meso- and macroplankton spatial distribution in summer period of 1980. In: Zats VV, Finenko ZZ (eds) Water dynamics and plankton productivity of the Black Sea (Dynamica vod i productivnost planktona Chernogo morya). Acad Sci USSR, Moscow, p 340-356 (in Russian)

Zaika VE (1973) Specific production of aquatic invertebrates. Wiley Interscience, London 